\title{
Isolation and molecular characterization of Mycoplasma spp. in sheep and goats in Egypt
}

\author{
Mounier M. Abdel Halium¹, Fayez A. Salib1ㅗ S. A. Marouf ${ }^{2}$ and Emil S. Abdel Massieh ${ }^{1}$
}

1. Department of Medicine and Infectious Diseases, Faculty of Veterinary Medicine, Cairo University, Giza, Egypt; 2. Department of Microbiology and Mycology, Faculty of Veterinary Medicine, Cairo University, Giza, Egypt.

Corresponding author: Emil S. Abdel Massieh, e-mail: emilsaad@cu.edu.eg

Co-authors: MMAH: mounirabdelhalium@gmail.com, FAS: fayez vetmed@hotmail.com, SAM: drsherif marouf@yahoo.com Received: 04-12-2018, Accepted: 15-03-2019, Published online: 13-05-2019

doi: 10.14202/vetworld.2019.664-670 How to cite this article: Abdel Halium MM, Salib FA, Marouf SA, Abdel Massieh ES (2019) Isolation and molecular characterization of Mycoplasma spp. in sheep and goats in Egypt, Veterinary World, 12(5): 664-670.

\section{Abstract}

Background and Aim: Different species of Mycoplasma are associated with many pathological problems in small ruminants including respiratory manifestation, this problem results in significant losses, especially in African countries. This study aimed to (I) study some epidemiological aspects of Mycoplasma species infections in Egyptian sheep and goats at Giza Governorate, (II) diagnosis of Mycoplasma species affections using bacterial isolation and identification, (III) apply the polymerase chain reaction (PCR) for typing of different Mycoplasma species, and (IV) illustrate the phylogenetic tree for the isolated Mycoplasma species and other species from GenBank using the purified PCR product.
\end{abstract}

Materials and Methods: A total of 335 samples were collected from sheep and goats from Giza Governorate in Egypt as 142 nasal swabs from clinically affected animals, 167 pneumonic lungs, 18 samples from tracheal bifurcation, and 8 samples by bronchial wash were cultured on pleuropneumonia-like organisms (PPLOs) media for cultivation of Mycoplasma species. PCR and sequencing and phylogenetic analysis were adopted to identify and classify the isolated Mycoplasma species.

Results: A total of 24 Mycoplasma isolates were isolated on PPLO media, identified by biochemical tests, and confirmed and typed by PCR using specific primers. 10 isolates were confirmed as Mycoplasma arginini, four isolates as Mycoplasma ovipneumoniae by PCR, and 10 isolates as undifferentiated Mycoplasma species. A purified isolate of M. arginini and M. ovipneumoniae was sequenced and phylogenetic analysis was illustrated.

Conclusion: M. arginini and M. ovipneumoniae are prevalent in Egyptian sheep and goats. Further studies on $M$. arginini are required due to its high frequency of isolation from pneumonic sheep and goats and also from animals suffer from different respiratory manifestations.

Keywords: goats, Mycoplasma, polymerase chain reaction, sequencing and phylogenetic analysis, sheep.

\section{Introduction}

Mycoplasma belongs to a group of bacteria named Mollicutes which characterized by its minute genome size and perpetually devoid of the cell wall [1]. Different Mycoplasma species are accompanying by many diseases and problems in both mammalian and avian species [2], sheep and goats (poor man's cow) are economically critical in many countries including Egypt as consumed for meat, wool, and milk production, more than $10 \%$ of meat production in Egypt is from sheep and goats [3].

Mycoplasma infections leading to a great economic loss due to it cause high morbidity and mortality rates in sheep and goats populations in African countries including Egypt, European countries, and India [4]. Mycoplasma causes various clinical manifestations as pneumonia, conjunctivitis, arthritis,

Copyright: Abdel Halium, et al. Open Access. This article is distributed under the terms of the Creative Commons Attribution 4.0 International License (http://creativecommons.org/licenses/ by/4.0/), which permits unrestricted use, distribution, and reproduction in any medium, provided you give appropriate credit to the original author(s) and the source, provide a link to the Creative Commons license, and indicate if changes were made. The Creative Commons Public Domain Dedication waiver (http:// creativecommons.org/publicdomain/zero/1.0/) applies to the data made available in this article, unless otherwise stated. and mastitis [5]. Mycoplasma species commonly associated with pneumonia in small ruminants are Mycoplasma ovipneumoniae, Mycoplasma arginini, Mycoplasma capri, Mycoplasma capripneumoniae, and Mycoplasma capricolum [6]. M. arginini is frequently isolated with $M$. ovipneumoniae from cases of atypical pneumonia in sheep and goats [5] and other cases with lung consolidation [7]. M. arginini is also isolated from other locations such as genital organs, eyes, and ears [8]; in addition, isolation of $M$. arginini from pathological cases in human $[9,10]$ gives suspicion that $M$. arginini may have zoonotic importance. In Egypt, different Mycoplasma species have been isolated including M. arginini, M. ovipneumoniae, and Mycoplasma agalactiae [11].

The respiratory problems are considered as multifactorial disease where interaction between different microbial agents such as bacteria (Pasteurella and Mycoplasma), viruses (PI3, reovirus, and adenovirus), and fungi and also other factors as host defense mechanism and environmental factors including climatic conditions and stress of transportations lead to increase the incidence of those problems [12].

Mycoplasma is highly fastidious microorganism required very precise media to develop in vitro, the 
low ability of Mycoplasma to form macromolecules needed for their growth refers to their evolutionary development from other bacteria; it is highly suspected that many Mycoplasmas exist in nature, however, have not been isolated due to their hard growth in vitro on artificial media [1].

Lately, the high development of polymerase chain reaction (PCR) technique makes the detection of different species of Mycoplasma using specific primers much simpler, till now, PCR remains the most valuable and rapid method for detecting specific species of Mycoplasma [13]. Moreover, the amplified purified PCR products of many genes from different strains can be sequenced, offering the chance for whole or partial typing of various species and strains at a more accurate level allowing molecular epidemiological studies and research.

The molecular epidemiological analysis allows the genotyping of different strains and has used in the tracing, control, and prevention of some diseases; also, molecular typing of some strains such as $M$. arginini would help in strain differentiation and then know the suspected pathological importance of these strains [8]. This study aimed to (I) study some epidemiological aspects of Mycoplasma species infections in Egyptian sheep and goats at Giza Governorate, (II) diagnosis of Mycoplasma species affections using bacterial isolation and identification, (III) apply the PCR for typing of different Mycoplasma species, and (IV) illustrate the phylogenetic tree for the isolated Mycoplasma species and other species from GenBank using the purified PCR product.

\section{Materials and Methods}

\section{Ethical approval}

Animal ethical approval was obtained from the Institutional Animal Care and Use Committee, Cairo University (II F 23 18).

\section{Animals and samples}

A total of 246 sheep and 89 goats of different ages, sexes, and breeds suffering from respiratory manifestations were examined clinically and bacteriology for isolation and identification of Mycoplasma species.

The present investigation was carried out between December 2015 and November 2016.

A total of 142 nasal swabs (58 sheep and 84 goats) and eight bronchial washes (seven sheep and one goat) were collected from sheep and goats suffering from respiratory manifestations in different localities at Giza Governorate. A total of 167 lung tissues (165 sheep and two goats) and 18 tracheal bifurcations (16 sheep and two goats) were collected from slaughtered sheep and goats at Monieb abattoir.

\section{Clinical examination}

Clinical signs of different respiratory manifestations in examined sheep and goats were recorded, a general examination of affected animals including body temperature was measured, cough test was applied, and chest auscultation was also adopted [14].

\section{Postmortem examination}

Lung tissues, tracheas, and tracheal bifurcation of slaughtered sheep and goats were examined to detect and record different pathological changes [15].

\section{Epidemiological investigation}

The prevalence of isolation of different Mycoplasma species in the examined sheep and goats was recorded according to species, ages, sexes, and season of the year [16].

\section{Bacterial isolation and identification of Mycoplasma species}

For nasal swab from living sheep and goats with respiratory manifestation, sterile cotton swabs were used to collect nasal swabs from nostrils of affected sheep and goats, and they were taken on pleuropneumonia-like organisms (PPLOs) broth placed in an icebox and submitted directly to the laboratory. Serial dilutions from nasal swab were formed and incubated on PPLO broth of $\mathrm{pH}$ 7.4-7.6 with $15 \%$ heat-inactivated swine serum, $10 \%$ fresh yeast extract, and $0.0005 \mathrm{~g} / \mathrm{ml}$ thallium acetate at $37^{\circ} \mathrm{C}$ for 3-7 days, then cultured on solid PPLO media by running drop technique [17].

For bronchial washes, approximately $1 \mathrm{~cm}$ long skin incision was done with a surgical scalpel over the midpoint of the trachea under local anesthesia of 2\% lidocaine with epinephrine, a 16-gauge hypodermic needle was inserted into the tracheal lumen. A catheter equipped with two-way lumen connect valve was then inserted through the needle up to bronchial bifurcation; approximately $20-50 \mathrm{ml}$ of Hank's balanced salt solution was injected through the catheter and then immediately aspirated with syringe. The debris was then removed by low-speed centrifugation; and then, samples were cultured on PPLO broth for 3-7 days at $37^{\circ} \mathrm{C}$ and then cultured on solid PPLO by running drop technique $[18,19]$.

For lung tissues and tracheal bifurcations from slaughtered sheep and goats, 167 samples from pneumonic areas and 18 samples from tracheal bifurcation were aseptically taken and placed in sterile plates kept in an icebox and were submitted to the laboratory. The outer surface of the pneumonic lungs was first seared with a heated spatula before cutting the inner surface of the lungs. Samples were taken either from bronchioles of each lobe of cut lung sections with micro tipped swabs or from lung homogenates by blending lung tissue with Hank's balanced salt solution followed by removal of debris by low-speed centrifugation., Samples were then cultured on PPLO broth for 3-7 days at $37^{\circ} \mathrm{C}$ and then cultured on solid PPLO by running drop technique; filter syringe of $0.45 \mathrm{~nm}$ pore diameter was used for filtration of cultured broth media before culturing on solid media.

Mild turbidity in liquid media of cultured samples and fried egg appearance after examination of plates under the microscope indicates mullicates growth [20]. 
PCR

For detection and typing of Mycoplasma species using PCR, positive cultures in liquid broth were centrifuged at 15,000 rpm for $10 \mathrm{~min}$, and the pellet was resuspended in $300 \mu \mathrm{l}$ of sterile distilled water, $300 \mu \mathrm{l}$ TNES buffer (20 mM Tris, pH 8.0, $150 \mathrm{mM}$ $\mathrm{NaCl}, 10 \mathrm{mM}$ Tris-ethylenediamine tetra-acetic acid, and $0.2 \%$ sodium dodecyl sulfate) and proteinase $\mathrm{K}$ $(200 \mu \mathrm{g} / \mathrm{ml})$ were then added to the bacterial suspension and kept at $56^{\circ} \mathrm{C}$ for $1 \mathrm{~h}$. The suspension was heated at $95^{\circ} \mathrm{C}$ for $10 \mathrm{~min}$ to inactivate proteinase $\mathrm{K}$ using a heat block method [20], the primer sequences, conditions of PCR, and the amplicon size with references are illustrated in Table-1 $[2,5,10,20]$.

\section{DNA sequencing and phylogenetic analysis}

For PCR product purification and sequencing, QIAquick PCR Product Extraction Kit (Qiagen Inc., Valencia, CA) was used for purification of the PCR product directly while a purified PCR product was sequenced in the forward and/or reverse directions on an Applied Biosystems 3130 automated DNA Sequencer (ABI, 3130, USA), using already available BigDye Terminator V3.1 sequencing kit (PerkinElmer/Applied Biosystems, Foster City, CA) [21].

A BLAST ${ }^{\circledR}$ analysis (Basic Local Alignment Search Tool) was initially performed to establish sequence identity to GenBank accessions. A comparative analysis of sequences was performed using the CLUSTAL W multiple sequence alignment program, version 1.83 of Meg Align module of Lasergene DNAStar software pairwise, which was designed by Thompson et al. [22] and phylogenetic analyses were done using maximum likelihood, neighbor-joining, and maximum parsimony in MEGA6 [23].

\section{Results}

\section{Clinical examination}

Living animals were examined clinically; animals were suffered from different signs of respiratory manifestations including fever $40-42^{\circ} \mathrm{C}$ with depression, nasal and ocular discharges (mucoid, mucopurulent, and purulent), cough, and abnormal chest sound with auscultation (Figure-1a and b).

\section{Postmortem examination}

The examined lungs, tracheas, and tracheal bifurcation showed different pathological lesions including congestion and edema with red and gray hepatization, hemorrhages in the trachea and tracheal bifurcation, and different degrees of pleurisy (Figure-1c).

\section{Some epidemiological data}

The results of isolation of different Mycoplasma species in the examined sheep and goats in relation to sex, season, and age are illustrated in Tables- 2 and 3 .

\section{Bacterial isolation and identification of Mycoplasma species}

The collected samples were considered positive to Mycoplasma species when bacterial growth was observed, and it was indicated by turbidity in PPLO broth and fried egg appearance colonies in the agar

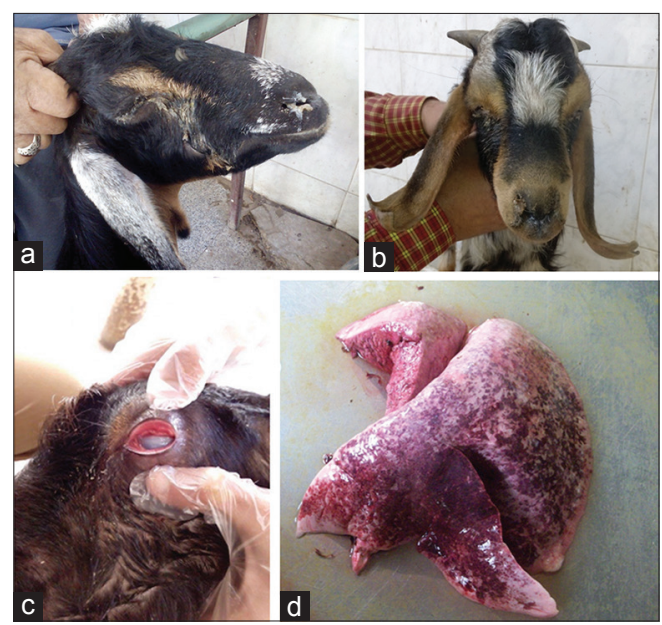

Figure-1: (a) Buck suffers from different respiratory manifestations with nasal and ocular discharges. (b) Goats suffer from severe respiratory distress with nasal and ocular discharge (corneal opacity). (c) Pneumonic sheep lung with areas of red hepatization, especially at the cranial lobe. (d) Colonies of Mycoplasma appear as a fried egg under the microscope.

Table-1: PCR primers, conditions, and amplicon size.

\begin{tabular}{|c|c|c|c|c|}
\hline Species & Primers & $\begin{array}{c}\text { Annealing } \\
\text { temperature }\end{array}$ & $\begin{array}{l}\text { Amplicon } \\
\text { size }\end{array}$ & References \\
\hline Mycoplasma genus & $\begin{array}{l}\text { GPO3F: 5'-TGGGGAGCAAACAGGATTAGATACC-3' } \\
\text { MGSO: 5'- TGCACCATCTGTCACTCTGTTAACCTC-3 }\end{array}$ & At $53^{\circ} \mathrm{C}$ for $15 \mathrm{~s}$ & 278 & [20] \\
\hline M. arginini & $\begin{array}{l}\text { MAGF: 5'-GCA TGG AAT CGCATG ATT CCT-3' } \\
\text { GP4R: 5'-GGT GTT CTT CCTTAT ATC TAC GC-3' }\end{array}$ & $46^{\circ} \mathrm{C}$ for $60 \mathrm{~s}$ & 525 & {$[10]$} \\
\hline M. ovipneumoniae & $\begin{array}{l}\text { MOVPF: 5'-GTT GGT GGC AAA AGTCACTAG-3' } \\
\text { MOVPR: 5'-CTT GACATC ACT GTT TCG CTG-3' }\end{array}$ & At $62^{\circ} \mathrm{C}$ for $90 \mathrm{~s}$ & 418 & {$[2]$} \\
\hline $\begin{array}{l}\text { Mycoplasma capricolum } \\
\text { subspecies capripneumoniae }\end{array}$ & $\begin{array}{l}\text { spe-F: 5'-ATCATIITAATCCCTTCAAG-3' } \\
\text { spe-R: 5'-TACTATGAGTAATTATAATATATGCAA-3' }\end{array}$ & $47^{\circ} \mathrm{C}$ for $15 \mathrm{~s}$ & 316 & {$[20]$} \\
\hline $\begin{array}{l}\text { Mycoplasma capricolum } \\
\text { subspecies capricolum }\end{array}$ & $\begin{array}{l}\text { MCCPL1-L: 5'-AGACCCAAATAAGCCATCCA-3' } \\
\text { MCCPL1-R: 5'-CTTTCACCGCTTGTTGAATG-3' }\end{array}$ & At $47^{\circ} \mathrm{C}$ for $15 \mathrm{~s}$ & 1350 & {$[5]$} \\
\hline $\begin{array}{l}\text { Mycoplasma mycoides } \\
\text { subspecies Capri }\end{array}$ & $\begin{array}{l}\text { P4: 5'-ACTGAGCAATTCCTCTT-3' } \\
\text { p5: 5'-TTAATAAGTCTCTATATGAAT-3' }\end{array}$ & At $46^{\circ} \mathrm{C}$ for $90 \mathrm{~s}$ & 195 & [5] \\
\hline M. agalactiae & $\begin{array}{l}\text { Mag-F: 5'-CCTITTAGATTGGGATAGCGGATG-3' } \\
\text { Mag-R: 5'-CCGTCAAGGTAGCGTCATTTCCTAC-3' }\end{array}$ & $60^{\circ} \mathrm{C}$ for $60 \mathrm{~s}$ & 360 & [5] \\
\hline
\end{tabular}

$\mathrm{PCR}=$ Polymerase chain reaction, $M$. arginine=Mycoplasma arginine, . agalactiae=Mycoplasma agalactiae, Mycoplasma ovipneumoniae $=M$. ovipneumoniae 
Table-2: Number and percentage of positive samples with Mycoplasma species in examined sheep and goats in relation to sex and season.

\begin{tabular}{|c|c|c|c|c|c|c|c|c|c|c|c|c|c|c|c|c|c|c|c|c|}
\hline \multirow[t]{3}{*}{ Samples } & \multirow[t]{3}{*}{ Sex } & \multicolumn{8}{|c|}{ Sheep } & \multicolumn{8}{|c|}{ Goats } & \multirow{2}{*}{\multicolumn{3}{|c|}{ Total }} \\
\hline & & \multicolumn{8}{|c|}{ Season } & \multicolumn{8}{|c|}{ Season } & & & \\
\hline & & \multicolumn{2}{|c|}{ Winter } & \multicolumn{2}{|c|}{ Spring } & \multicolumn{2}{|c|}{ Summer } & \multicolumn{2}{|c|}{ Autumn } & \multicolumn{2}{|c|}{ Winter } & \multicolumn{2}{|c|}{ Spring } & \multicolumn{2}{|c|}{ Summer } & \multicolumn{2}{|c|}{ Autumn } & & & \\
\hline \multirow{2}{*}{ Nasal } & Male & 12 & 1 & 10 & 1 & 8 & 1 & 9 & 0 & 17 & 2 & 14 & 1 & 9 & 1 & 14 & 1 & 93 & 8 & \\
\hline & Female & 6 & 0 & 4 & 0 & 3 & 0 & 6 & 1 & 9 & 1 & 8 & 1 & 6 & 0 & 7 & 0 & 49 & 3 & \\
\hline \multirow{2}{*}{$\begin{array}{l}\text { Bronchial } \\
\text { wash }\end{array}$} & Male & 2 & 1 & 1 & 0 & 1 & 0 & 1 & 0 & 1 & 0 & - & - & - & - & - & - & 6 & 1 & \\
\hline & Female & 1 & 0 & - & - & - & - & 1 & 0 & - & - & - & - & - & - & - & - & 2 & 0 & \\
\hline \multirow{2}{*}{$\begin{array}{l}\text { Tracheal } \\
\text { bifurcation }\end{array}$} & Male & 4 & 1 & 3 & 0 & 2 & 0 & 3 & 0 & 1 & 1 & - & - & - & - & - & - & 13 & 2 & \\
\hline & Female & 1 & 0 & 1 & 0 & - & - & 2 & 1 & - & - & - & - & - & - & 1 & 0 & 5 & 1 & \\
\hline \multirow[t]{2}{*}{ Lung } & Male & 31 & 2 & 28 & 2 & 21 & 1 & 23 & 1 & 1 & 0 & - & - & - & - & - & - & 104 & 6 & \\
\hline & Female & 21 & 1 & 16 & 1 & 13 & 0 & 12 & 0 & - & - & - & - & - & - & 1 & 1 & 63 & 3 & \\
\hline \multicolumn{2}{|l|}{ Total } & 78 & 6 & 63 & 4 & 48 & 2 & 57 & 3 & 29 & 4 & 22 & 2 & 15 & 1 & 23 & 2 & $\begin{array}{l}0216 \\
119\end{array}$ & $\begin{array}{c}17 \\
7\end{array}$ & $\begin{array}{l}7.78 \% \\
5.88 \%\end{array}$ \\
\hline \multicolumn{2}{|c|}{$\begin{array}{l}\text { Percentage of } \\
\text { positive samples }\end{array}$} & \multicolumn{2}{|c|}{7.7} & \multicolumn{2}{|c|}{6.35} & \multicolumn{2}{|c|}{4.16} & \multicolumn{2}{|c|}{5.26} & \multicolumn{2}{|c|}{13.8} & \multicolumn{2}{|c|}{9.1} & \multicolumn{2}{|c|}{6.67} & \multicolumn{2}{|c|}{8.7} & & & \\
\hline
\end{tabular}

Table-3: Distribution of Mycoplasma species in examined sheep and goats in relation to age.

\begin{tabular}{|c|c|c|c|c|c|c|}
\hline \multirow[t]{2}{*}{ Age } & \multicolumn{2}{|r|}{ Sheep } & \multicolumn{2}{|r|}{ Goats } & Total & \multirow[b]{2}{*}{$\begin{array}{c}\text { Percentage of } \\
\text { positive samples }\end{array}$} \\
\hline & $\begin{array}{c}\text { Number of } \\
\text { samples }\end{array}$ & $\begin{array}{c}\text { Number of } \\
\text { positive samples }\end{array}$ & $\begin{array}{c}\text { Number of } \\
\text { samples }\end{array}$ & $\begin{array}{c}\text { Number of } \\
\text { positive samples }\end{array}$ & $\begin{array}{c}\text { Number of } \\
\text { positive samples }\end{array}$ & \\
\hline$<15$ months & 102 & 7 & 29 & 4 & 11 & 8.37 \\
\hline $\begin{array}{l}\text { From } 15 \text { months to } \\
21 \text { months }\end{array}$ & 79 & 5 & 33 & 3 & 8 & 7.14 \\
\hline $\begin{array}{l}\text { From } 21 \text { months to } \\
27 \text { months }\end{array}$ & 34 & 2 & 14 & 1 & 3 & 6.25 \\
\hline$>27$ months & 31 & 1 & 13 & 1 & 2 & 4.54 \\
\hline
\end{tabular}

plates (Figure-1d). Bacterial growth was observed in 24 samples (15 from sheep and nine from goats). Biochemically, all the 24 samples showed zones of growth inhibition around digitonin discs $5 \mathrm{~mm}$ in diameter or more, 14 were glucose fermentation test positive, and 10 samples were arginine hydrolysis positive.

PCR

The total of 24 culture-positive isolates was confirmed as belonging to the Mycoplasma genus (Figure-2a) by the group-specific PCR, which produced specific bands with the molecular size of 278 bp.

In $M$. arginini-specific PCR amplification of the samples, six of the sheep isolates and four of the goat isolates produced positive products with the approximate molecular size of 525 bp (Figure-2b). The isolation percentages of $M$. arginini were, therefore, calculated as $40 \%(6 / 15)$ in sheep and $44.4(4 / 9)$ in goats.

In M. ovipneumoniae-specific PCR amplification of the samples, three of the sheep isolates and one of the goat isolates produced positive products with the approximate molecular size of $418 \mathrm{bp}$ (Figure-2c). The isolation percentages of $M$. ovipneumoniae in related to total Mycoplasma isolates were, therefore, calculated as 20\% (3/15) in sheep and $11.11(1 / 9)$ in goats.

The other 10 isolates which were positive with the general primer of Mycoplasma genus were tested against (M. capricolum subspecies capripneumoniae,
M. capricolum subspecies capricolum, Mycoplasma mycoides subspecies capri, and $M$. agalactiae) using species-specific primers and were negative, the 10 samples considered as undifferentiated Mycoplasma species (Table-4).

The high-frequency rate of isolation of $M$. arginini from sheep and goats suffering from respiratory manifestations and pneumonic lungs makes us more interested, amplified purified PCR product of one isolate was subjected to sequencing analysis and the sequence then was submitted to NCBI GenBank taking accession number of MH685445 and also, purified PCR product of one isolate of $M$. ovipneumoniae was subjected to sequencing analysis and the sequence then submitted to NCBI GenBank taking accession number of MK045665.

\section{Phylogenetic analysis}

A phylogenetic tree (Figure-3a and b) was formed based on $16 \mathrm{~S}$ gene sequence of one purified strain of each species from the Egyptian isolates and other isolates of $M$. arginini and $M$. ovipneumoniae isolated from different countries and different species (from GenBank). Sequencing of $16 \mathrm{~S}$ genes of $M$. arginini and $M$. ovipneumoniae Egyptian isolate and other isolates from other countries showed no significant difference between them.

\section{Discussion}

Mycoplasmas of different species have been implicated in causing various diseases in sheep and 

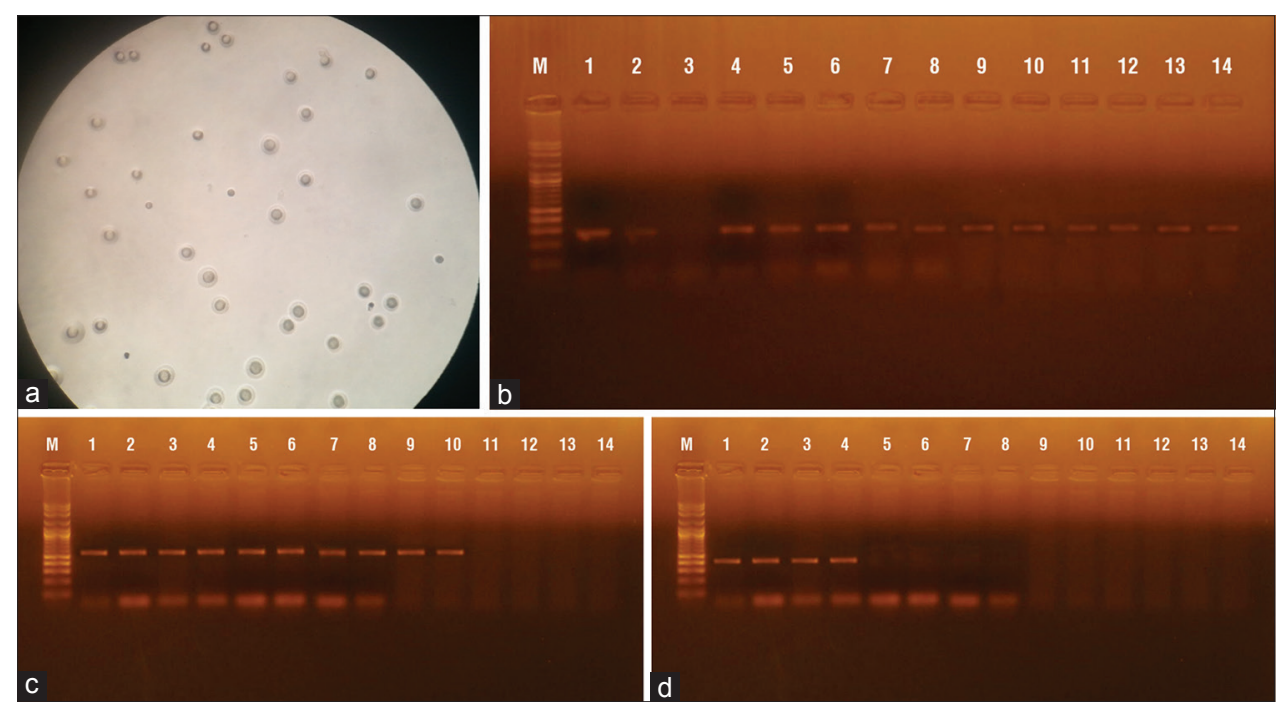

Figure-2: (a) Agarose gel of conventional polymerase chain reaction for detection of $16 \mathrm{~S}$ gene using Mycoplasma genusspecific primer at amplicon size 278 bp. Lane M (Molecular weight marker, 100-1000 bp); Lanes 1-14, positive samples except for lane 3 negative control. (b) Agarose gel of conventional polymerase chain reaction for detection of Mycoplasma arginini species at amplicon size 525 bp. Lane M (Molecular weight marker, 100-1000 bp); Lanes 1-10 positive. (c) Agarose gel of conventional polymerase chain reaction for detection of Mycoplasma ovipneumoniae at amplicon size 418 bp. Lane M, (Molecular weight marker, 100-1000 bp); lanes 1-4 positive samples.

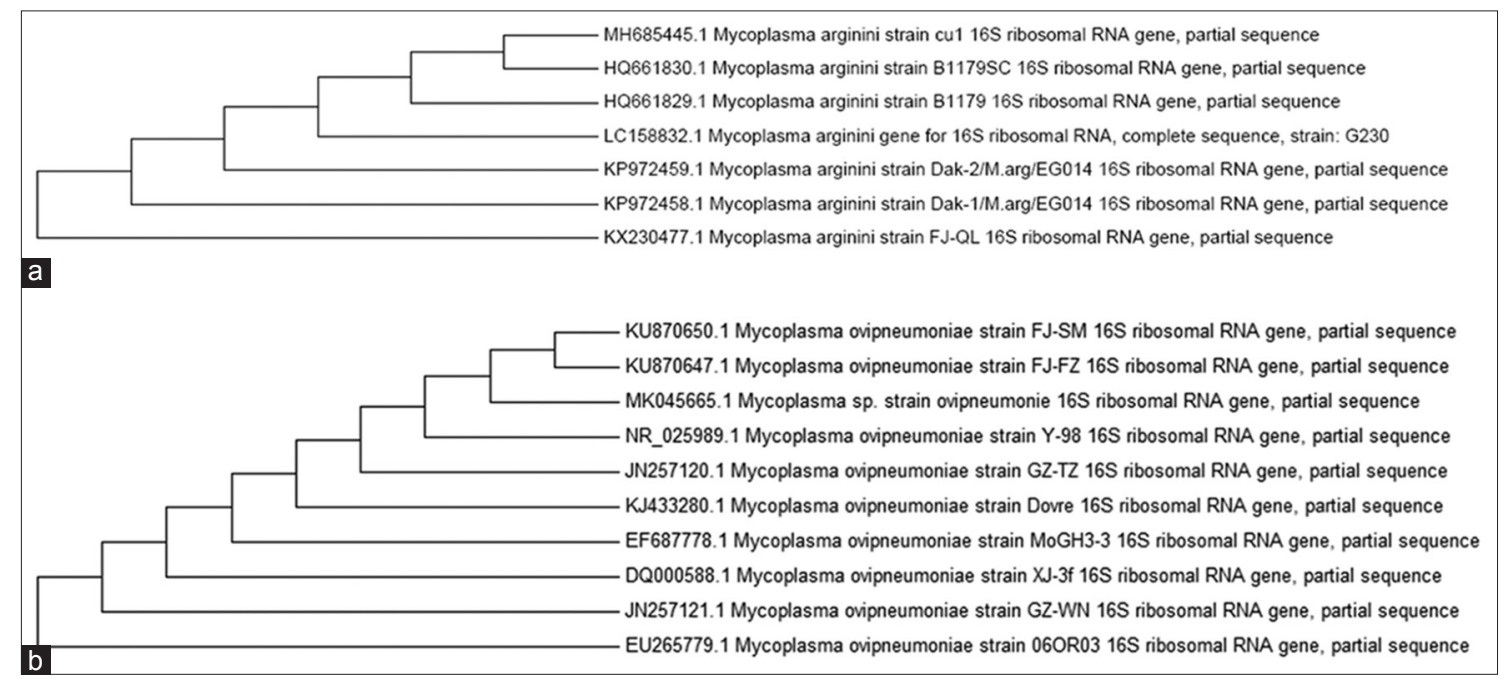

Figure-3: (a) Phylogenetic analysis of Mycoplasma arginini isolates based on $16 \mathrm{~S}$ gene sequences, MH685445 isolate under study, KP972459 and KP972459 strains isolated from goats in Egypt, HQ661830 and HQ661829 strains from sheep in South Africa, LC158832 from sheep in Japan, and KX2304770 from goat in China. (b) Phylogenetic analysis of M. ovipneumoniae isolates based on 16S gene sequence, KU870650 and KU870647 strains isolated from goats in China, JN257120, EF687778, DQ0000588, and JN257121 from sheep in China, NR_025989 from wild sheep (Ovis aries) in the USA and EU265779 from bighorn sheep in the USA and KJ433280 from Norwegian Muskov in Norway.

goats including different respiratory manifestations, joint affection, conjunctivitis, and mastitis. The most common species isolated from small ruminants are M. mycoides cluster as Mycoplasma capricolum subspecies capripneumoniae the causative agent of contagious caprine pleuropneumonia, other species isolated from sheep and goats including Mycoplasma ovipneumoniae [24]; however, M. arginini has been isolated from a different pathological condition in small ruminants including pneumonia $[17,25]$.

In this study, 335 samples including lung tissue, nasal swab, tracheal bifurcation, and bronchial wash were collected from sheep and goats in Egypt to isolation, identification, and classification of different Mycoplasmas species; Mycoplasma were isolated from 24 samples identified biochemically using digitonin, confirmed using PCR as Mycoplasma using Mycoplasma genus-specific primers.

The results obtained in this study showed that the prevalence rate of Mycoplasma species was higher in goats than sheep. In Egypt, similar finding has been reported by Ammar et al. [11]; the occurrence of Mycoplasma was more frequently in young animals than adult; these findings are closely related to Elshafay et al. [26] who found higher percent of isolation in young animals than adult, especially in goats in 


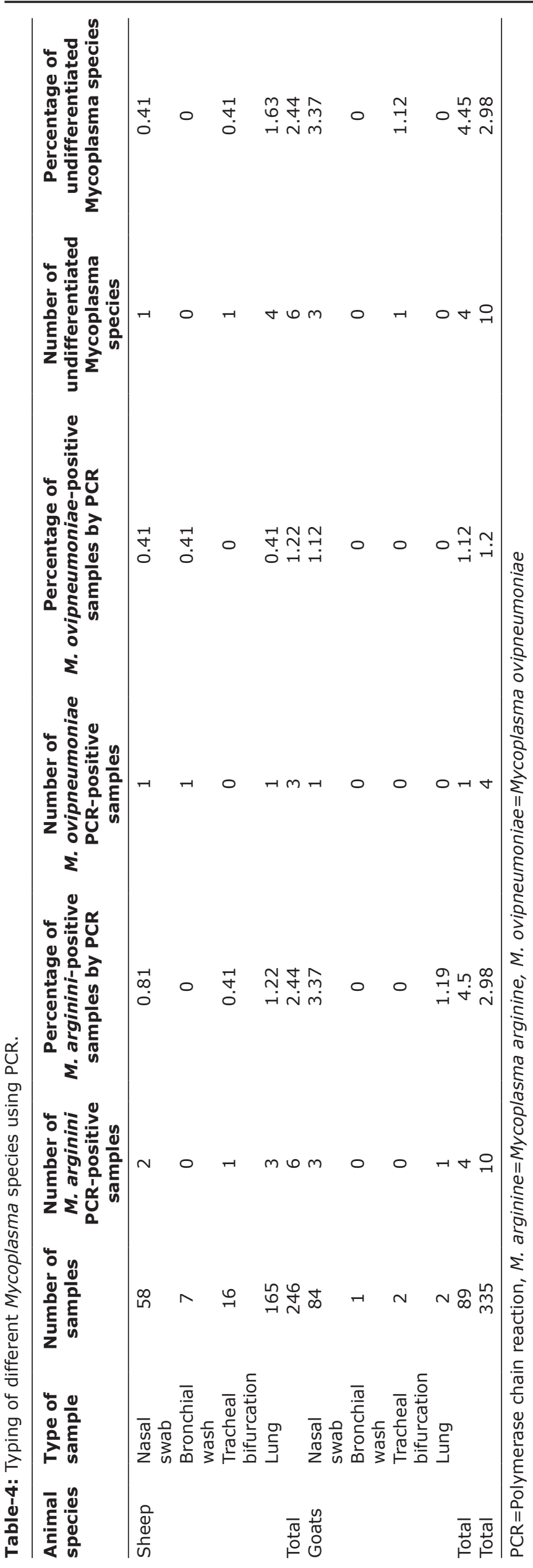

Giza and Dakahlia Governorates. Analysis of obtained data on seasonal occurrence of Mycoplasma revealed higher occurrence in winter months (cold weather) than in summer months (hot weather) may be due to increasing stress factor at cold weather and grouping of animals and direct contact with each other. Ten samples were confirmed as $M$. arginini (2.98\%) and four samples as M. ovipneumoniae $(1.19 \%)$ by PCR using specific primer for each species, these results disagreed with Elshafay et al. [26] who recorded higher infection rates.

The high-frequency rate of isolation of M. arginini from different pathological cases in small ruminants, especially from pneumonic cases, and cases suffer from different respiratory manifestations $[7,11,17,25]$ may refer to its pathogenic role in respiratory affections.

Experimental infection of goats $<1$-year aged by $M$. arginini isolates formed by Chinedu et al. [6] indicates that $M$. arginini have some pathogenic effect as all experimental animals suffered from cough and nasal discharges, on postmortem examination mild-to-severe congestion of lungs with lung edema. Histopathological abnormalities observed were acute interstitial pneumonia, hyperemia of pulmonary capillaries with sever infiltration with leucocytes in the interstitial tissues, and alveoli.

For estimation, the relationship between $M$. arginini and $M$. ovipneumoniae isolated from different species and different countries one purified isolate of each species from sheep pneumonic lungs was submitted for partial sequencing of $16 \mathrm{~S}$ gene which showed $>99 \%$ sequence identity with different $M$. arginini and M. ovipneumoniae isolates from different species (sheep, goats, and wild ruminants) and different countries, phylogenetic analysis of $16 \mathrm{~S}$ gene showed very high sequence identity between different strains regardless their geographical distribution.

\section{Conclusion}

It was concluded that although the respiratory problem in small ruminant is very complex, as many factors play a role including infectious agents and predisposing factors, the high-frequency isolation of M. arginini from different respiratory manifestation and pneumonic lungs suspect its pathogenic role.

\section{Authors' Contributions}

MMA and FAS designed the experiment protocol and the study. ESA and SAM collected and analyzed the samples. All authors were involved in data analysis, scientific discussion, and writing of the manuscript. All authors read and approved the final manuscript.

\section{Acknowledgments}

The study is funded by the Faculty of Veterinary Medicine, Cairo University, Egypt. 


\section{Competing Interests} interests

The authors declare that they have no competing

\section{Publisher's Note}

Veterinary World remains neutral with regard to jurisdictional claims in published institutional affiliation.

\section{References}

1. Nicholas, R., Ayling, R. and McAuliffe, L. (2008) Respiratory diseases of small ruminants. In: Mycoplasma Diseases of Ruminants. $1^{\text {st }}$ ed. CABI International, Oxfordshire, UK. p169-198.

2. Glen, C.W., Mark, L.D., Frances, E.C. and Alton, C.S.W. (2012) Detection of Mycoplasma ovipneumoniae and M. arginini in bighorn sheep using enrichment culture coupled with genus and species-specific polymerase chain reaction. J. Wildl. Dis., 48(2): 449-453.

3. Hakim, A.S., Bakry, M.A., Nagwa, S.S.A. and Mona, S.Z. (2014) Role of molecular techniques in the characterization of bacteria causing pneumonia in small ruminants. Life Sci. J., 11(6): 147-153.

4. Sandip, C., Amit, K., Ruchi, T., Anu, R., Yash, M., Kuldeep, D., Amar, P. and Minakshi, P. (2014) Advances in the diagnosis of respiratory diseases of small ruminants. Vet. Med. Int., 2014: 508304.

5. Kumar, V., Rajneesh, R., Somya, M. and Pramod, K.R. (2013) Isolation and characterization of Mycoplasma mycoides subspecies capri from milk of natural goat mastitis cases. ISRN Vet. Sci., 2013: 593029.

6. Chinedu, A.A., Kennedy, F.C., Stephen, I.O. and Jude, S.R. (2016) Pathogenicity of local isolates of Mycoplasma ovipneumoniae and Mycoplasma arginini in experimental West African dwarf goats. J. Adv. Vet. Anim. Res., 3(3): 242-251.

7. Fernández, S., Galapero, J., Rey, J., Pérez, C.J., Ramos, A., Rosales, R., Ayling, R., Alonso, J.M., Gómez, L. (2016) Investigations into the seasonal presence of Mycoplasma species in fattening lambs. Vet. J., 212: 80-82.

8. Olusola, M.O., Anna, K., Stuart, R.B., Kelly, A.T., Philip, F.M., Marc, S.M. and Glenn, F.B. (2015) Genetic diversity of Mycoplasma arginini isolates based on multilocus sequence typing. Vet. Microbiol., 180(1-2): 123-128.

9. Mayumi, W., Shigemi, H., Miki, G. and Yuichi, H. (2017) Bloodstream infection due to Mycoplasma arginini in an immunocompromised patient. J. Clin. Microbiol., 50(9): 3133-3135.

10. Pálma, S., Dóra, P, Eszter, O., Mercedes, M., Norbert, W., Katinka, P., Dmitriy, V.V., Vladimir, E.C., Susan, S., Laszlo, S. and Sarolta, K. (2018) Eosinophilic fasciitis associated with Mycoplasma arginini infection. J. Clin. Microbiol., 50(3): 1113-1117.

11. Ammar, A.M., Eissa, S.I., El-Hamid, M.I.A., Ahmed, H.A. and ElAziz, A.E.E. (2008) Advanced study on Mycoplasmas isolated from sheep. Zag. Vet. J., 36: 128-137.

12. Azizi, S., Tajbakhsh, E., Rezaii, A., Nekouei, S.H. and Namjoo, A.R. (2011) The role of Mycoplasma ovipneumoniae and Mycoplasma arginini in pneumonic lungs of slaughtered sheep. Rev. Méd. Vét., 162(6): 310-315.

13. Awan, M.A., Ferhat, A., Masoom, Y.Z., Mohammad, M.T., Masroor, A.B., Mohammad, A.A., Zafar, A., Nadeem, R., Majed, R. and Mohammad, S. (2012) Prevalence of Mycoplasma species by polymerase chain reaction (PCR) directly from the nasal swab samples of goats. Pak. J. Life Soc. Sci., 10(1): 5-12.

14. Jackson, P.G.G. and Cockcroft, P.D. (2008) Clinical Examination of Farm Animals. Blackwell Publishing, Oxford, UK.

15. Wäsle, K., Pospischil, A., Hässig, M., Gerspach, C. and Hilbe, M. (2017) The post-mortem examination in ruminants and its possible benefit to ruminant clinical medicine. J. Comp. Pathol., 156(2-3): 202-216.

16. Thrusfield, M.V. and Robert, C. (2018) Veterinary Epidemiology. $4^{\text {th }}$ ed. Blackwell Publishing, Oxford, UK.

17. Valsala, R., Rana, R., Remesh, A.T. and Singh, V.P. (2017) Mycoplasma arginini: High frequency involvement in goat pneumonia. Turk. J. Vet. Anim. Sci., 41(1): 393-399.

18. Voigt, K., Brugmann, M., Huber, K., Dewar, P., Cousens, C., Hall, M., Sharp, J.M. and Ganter, M. (2007) PCR examination of bronchoalveolar lavage samples is a useful tool in pre-clinical diagnosis of ovine pulmonary adenocarcinoma (Jaagsiekte). Res. Vet. Sci., 83(3): 419-427.

19. Ponnusamy, P., Samuel, B.M.R., Ranjith, K.M. and Manickam, R. (2017) Isolation, identification and antibiogram of Mannheimia haemolytica associated with caprine pneumonia in the Cauvery delta region of Tamil Nadu, India. Int. J. Curr. Microbiol. Appl. Sci., 6(9): 3118-3122.

20. Çetinkaya, B., Kalin, R., Karahan, M., Atil, E., MansoSilván, L. and Thiaucourt, F. (2009) Detection of contagious caprine pleuropneumonia in East Turkey. Rev. Sci. Tech., 28(3): 1037-1044.

21. Altschul, S.F., Gish, W., Miller, W., Myers, E.W. and Lipmanl, D.J. (1990) Basic local alignment search tool. J. Mol. Biol., 215(3): 403-410.

22. Thompson, J.D., Higgins, D.G. and Gibson, T.J. (1994) CLUSTAL W: Improving the sensitivity of progressive multiple sequence alignment through sequence weighting, position-specific gap penalties and weight matrix choice. Nucleic Acids Res., 22(22): 4673-4680.

23. Tamura, K., Stecher, G., Peterson, D., Filipski, A. and Kumar, S. (2013) MEGA6: Molecular evolutionary genetics analysis version 6.0. Mol. Biol. Evol., 30(12): 2725-2729.

24. Yatoo, M.I., Oveas, R.P., Masood, S.M., Sabiya, Q., Zahid, A.K., Mir, N., Mujeeb, U.R.F., Noor, A.T., Maheshwar, S.K., Sandip, C., Kuldeep, D. and Rajneesh, R. (2018) Mycoplasmosis in small ruminants in India. J. Exp. Biol. Agric. Sci., 6(2): 264-281.

25. Andrea, D.P., Daniela, A., Katiuscia, Z., Giuseppe, M. and Massimo, S. (2017) Mycoplasma pneumonia in small ruminants: A ten-year long retrospective survey. Small Rumin. Res., 153: 103-106.

26. Elshafay, D.Y., Nermin, A., Yasser, F.E. and Emad, E.Y. (2016) Isolation and Molecular Characterization of Mycolplasma arginini Isolated from Sheep and Goats with Respiratory Manifestation in Dakahilia Governorate. $3^{\text {rd }}$ Conference of the Scientific Research Institute of Animal Society. Vol. 3. Modern Trends Health for the Advancement of Animal Health, Egypt, Giza.

\section{$* * * * * * * *$}

